\title{
Multiweek Experiments for an Inorganic Chemistry Laboratory Course: Synthesis of Nickel Complexes Supported by a Tetradentate Ligand with an $\mathrm{N}_{2} \mathrm{O}_{2}$ Donor Set
}

Joel D. Collett, Jeanette A. Krause, and Hairong Guan*

Department of Chemistry, University of Cincinnati, P.O. Box 210172, Cincinnati, Ohio 45221-0172, United States

\section{ABSTRACT}

Inorganic Chemistry teaches students the concept that modifications to ligand structures, especially the donor properties, can have a drastic impact on the reactivity and stability of the metal complexes.

Experiments described here reinforce this concept through the investigation of two tetradentate ligands derived from o-phenylenediamine and salicylaldehyde. The Schiff base ligand, $\mathrm{H}_{2}$ salophen, reacts with $\mathrm{Ni}(\mathrm{OAc})_{2} \bullet 4 \mathrm{H}_{2} \mathrm{O}$ to yield a maroon colored, square planar complex, Ni(salophen). Under the same conditions, the amine-type ligand, $\mathrm{H}_{2}$ salophan, forms a light-blue compound with a formula $\mathrm{Ni}($ salophan)(HOAc). Complex Ni(salophan) free of acetate may be produced from the reaction of $\mathrm{H}_{2}$ salophan with $\mathrm{Ni}(\mathrm{OAc})_{2} \bullet 4 \mathrm{H}_{2} \mathrm{O}$ in the presence of $\mathrm{NaOH}$, but undergoes ligand dehydrogenation to yield Ni(salophen). Students conducting these experiments have the opportunity to learn synthetic techniques and various characterization methods. Most importantly, the inquiry-guided experimental design helps them develop critical thinking skills and apply acquired knowledge to solving a research problem in a laboratory course.

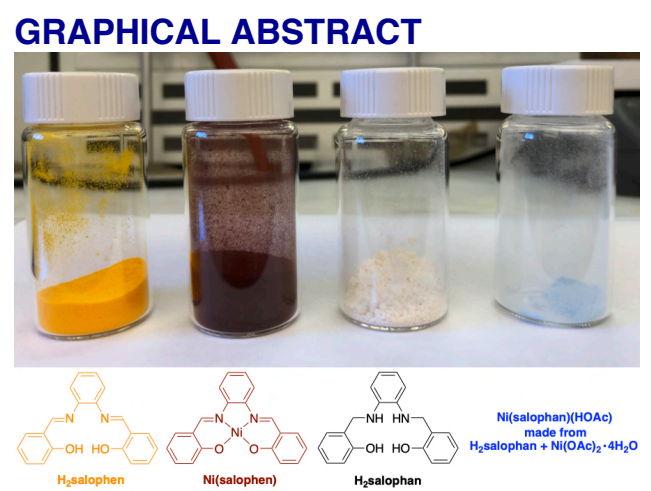




\section{KEYWORDS}

Upper-Division Undergraduate, Inorganic Chemistry, Laboratory Instruction, Hands-On

Learning/Manipulatives, Inquiry-Based/Discovery Learning, IR Spectroscopy, Mass Spectrometry,

Molecular Properties/Structure, NMR Spectroscopy, X-ray Crystallography

\section{INTRODUCTION}

Tetradentate Schiff base ligands bearing an $\mathrm{N}_{2} \mathrm{O}_{2}$ donor set are popular building blocks for constructing metal complexes used as enzyme mimics, ${ }^{1}$ therapeutics, ${ }^{2}$ catalysts, ${ }^{3}$ and novel materials. ${ }^{4}$ $N, N$-bis(salicylidene)ethylenediamine ( $\mathrm{H}_{2}$ salen), arguably the best-known ligand in this class, can be readily prepared from the condensation reaction between ethylenediamine and 2 equiv of salicylaldehyde (eq 1). This synthetic strategy is applicable to a wide variety of diamines and salicylaldehyde derivatives, providing an excellent opportunity to tune the steric and electronic properties of the ligands. It is thus not surprising that the coordination chemistry of these Schiff base ligands has been continuously and extensively explored with virtually every transition metal in the periodic table.

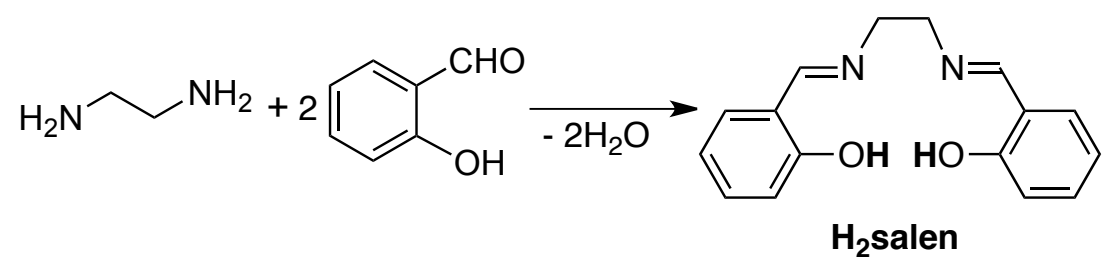

The imine functionalities of the Schiff base ligands are reducible to amine groups, often accomplished by using a mild reducing agent such as $\mathrm{NaBH}_{4}$. The products may still serve as $\mathrm{N}_{2} \mathrm{O}_{2}$ tetradentate ligands; however, the donor properties are significantly altered. In particular, the nitrogen sites change from good $\pi$-acceptors (for imines) to pure $\sigma$-donors (for aliphatic amines). Saturation of the $\mathrm{C}=\mathrm{N}$ bonds also renders the ligand backbone more flexible, which can have a profound impact on the geometry and the stability of the metal complexes. In contrast to the numerous reports on $\mathrm{M}$ (salen)-type complexes, transition metal complexes supported by the saturated $\mathrm{N}_{2} \mathrm{O}_{2}$ tetradentate ligands have been studied only sporadically. ${ }^{5}$ influenced by ligand field and coordination geometry. Four-coordinate Ni(II) complexes, for instance, 
are diamagnetic $(S=0)$ with a square planar geometry when the ligands are sufficiently $\pi$-accepting, and the classical example is $\left[\mathrm{Ni}(\mathrm{CN})_{4}\right]^{2-}$. With a weak-field ligand like chloride, $\left[\mathrm{NiCl}_{4}\right]^{2-}$ is paramagnetic $(S=1)$ and adopts a tetrahedral geometry. This important concept can be reinforced in an inorganic laboratory course using the $\mathrm{N}_{2} \mathrm{O}_{2}$ tetradentate ligands described above. The reactivities of $\mathrm{M}$ (salen)-type complexes have been previously developed as laboratory course materials, although the emphasis was placed on teaching how small molecules mimic enzymes. ${ }^{6}$ The experiments discussed herein, which were successfully implemented and refined at the University of Cincinnati in 2018-2020 (for CHEM4020L - Inorganic Chemistry Laboratory), focus more on synthesis and characterization, specifically in the context of studying nickel complexes.

To discourage the practice of finding answers by simply using web search engines, $N, N^{\prime}-$ bis(salicylidene)-1,2-phenylenediamine ( $\mathrm{H}_{2}$ salophen) is chosen over the more searchable $\mathrm{H}_{2}$ salen as the starting ligand. ${ }^{7}$ The reagents needed for the experiments are relatively inexpensive, and the time required for making each ligand or nickel complex is conveniently short (30-60 min), which, in a typical 3-hour laboratory session, leaves students ample time to learn various characterization techniques. The later step of the synthesis involves a reaction of the saturated $\mathrm{N}_{2} \mathrm{O}_{2}$ tetradentate ligand ( $\mathrm{H}_{2}$ salophan) with $\mathrm{Ni}(\mathrm{OAc})_{2} \bullet 4 \mathrm{H}_{2} \mathrm{O}$, which leads to an open-ended project due to the ambiguity of the structure for the isolated product. Students are guided to design additional experiments and propose analytical tools to decipher what the nickel complex might look like.

\section{LEARNING OBJECTIVES}

The synthetic part of the experiments strengthens the basic techniques such as weighing, mixing, refluxing, vacuum filtration, and recrystallization that students may have already learned from general and organic chemistry laboratory courses. The analytical part of the experiments focuses on training in IR and NMR spectroscopy, complemented by mass spectrometry (MS), elemental analysis (EA), and X-ray crystallography that students are less familiar with. Additional pedagogical objectives, specifically for an upper-division laboratory course, include the following:

(1) enhance the understanding of ligand field theory with real-life examples;

(2) develop critical thinking skills through designing experiments;

(3) learn how to search the chemical literature and know that the literature could be wrong. 


\section{DESCRIPTION OF THE EXPERIMENTS}

The experiments are divided into activities for 3-hour laboratory sessions spanning 5 weeks. For the course offered at the University of Cincinnati, 12-24 students were enrolled each year, mostly chemistry or biochemistry majors with a few pre-pharmacy students. For a larger class or if limited by instrumentation, instructors may consider pairing students. The reagents and glassware needed for the synthesis are readily available in most chemistry laboratories or from multiple vendors at affordable prices. Each compound synthesized by our students was analyzed by IR and ${ }^{1} \mathrm{H}$ NMR spectroscopy; however, in the interest of time and cost, only one representative sample from the class was selected for ${ }^{13} \mathrm{C}\{1 \mathrm{H}\} \mathrm{NMR}$, mass spectral, elemental, or X-ray crystallographic analysis. Students were provided with the experiment guide and safety data sheets (SDS) for the chemicals to be used, typically 5 days before the scheduled laboratory session. Prior to the laboratory work, they were required to complete a pre-lab quiz, which was intended to test their preparation for the experiments and understanding of potential safety hazards. As assessments, a post-lab assignment mainly on processing NMR data was given following the Week 2 experiments, and instructions for a combined lab report were provided following the Week 3 experiments.

Week 1: Synthesis of the $\mathrm{H}_{2}$ salophen Ligand

First, a short pre-lab lecture should be delivered to emphasize the importance of observing safety guidelines, appropriate ways of disposing chemical waste and used gloves, and the expectation for the multiweek experiments. Students can then proceed with the synthesis of the Schiff base ligand from salicylaldehyde and o-phenylenediamine (eq 2). The condensation reaction has been reported to take place in ethanol under refluxing conditions for $2-12 \mathrm{~h}^{8}$ or at room temperature for $12 \mathrm{~h} .{ }^{9}$ In our students' hands, the room-temperature reaction was complete in $30 \mathrm{~min}$. It is, however, recommended to perform the synthesis in refluxing ethanol for $15 \mathrm{~min}$, because at room temperature both $o$-phenylenediamine and $\mathrm{H}_{2}$ salophen are poorly dissolved. ${ }^{10}$ The orange precipitate can be collected by vacuum filtration, washed with ethanol, and dried in air. It is important to remind students that a wet product will negatively impact the subsequent steps because the amount of $\mathrm{H}_{2}$ salophen used will be overestimated. The identity and purity of the isolated product can be 
confirmed by ${ }^{1} \mathrm{H}$ and ${ }^{13} \mathrm{C}\left\{{ }^{1} \mathrm{H}\right\}$ NMR spectroscopy. For students who have not prepared an NMR sample before, a short NMR lecture is needed in class, especially on the sensitivity of the technique and the reason for using a deuterated solvent.

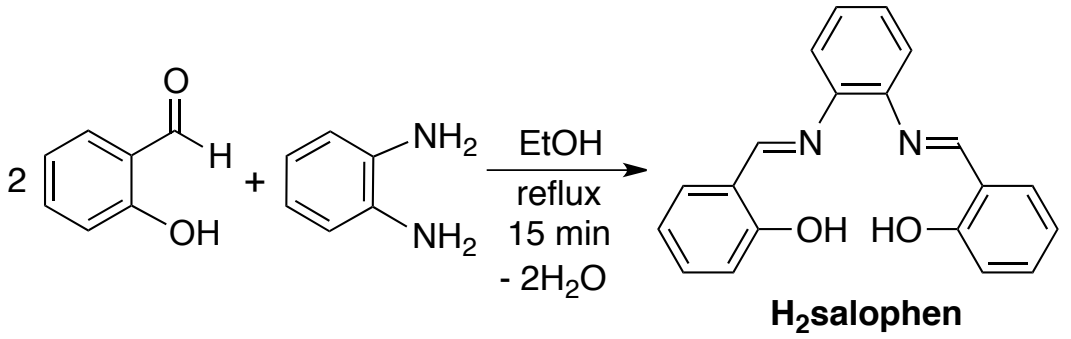

\section{Week 2: Synthesis of the Ni(salophen) Complex}

If students have not previously learned how to process raw NMR data, instructors should consider starting the second week with a tutorial on how to use MestreNova/Mnova or a vendor-specific NMR software like Topspin. The experimental part of the class involves refluxing a $1: 1$ mixture of $\mathrm{H}_{2}$ salophen and $\mathrm{Ni}(\mathrm{OAc})_{2} \bullet 4 \mathrm{H}_{2} \mathrm{O}$ in ethanol (eq 3), which results in an immediate color change from orange to dark red. Reported synthetic methods for Ni(salophen) mention a reaction time of 1-2 h. ${ }^{11}$ This was deemed to be unnecessary by our students; we found that the reaction was actually complete in $20 \mathrm{~min}$. The nickel complex can be isolated as a maroon powder following a work-up procedure similar to that used for $\mathrm{H}_{2}$ salophen. Like the ligand, Ni(salophen) can be analyzed by ${ }^{1} \mathrm{H}$ and ${ }^{13} \mathrm{C}\left\{{ }^{1} \mathrm{H}\right\}$ NMR spectroscopy for its identity and purity. In our experience, students understandably took longer to complete the task in Week 1. For that reason, characterization of $\mathrm{H}_{2}$ salophen by IR spectroscopy was postponed to Week 2, when the IR spectrum of the newly prepared Ni(salophen) was also recorded. This plan has an additional advantage, because students are able to immediately note the spectral change after complexation. The success of nickel coordination can be further confirmed by analyzing the NMR data of both $\mathrm{H}_{2}$ salophen and Ni(salophen), which is recommended as a post-lab assignment for practicing using the NMR software. 

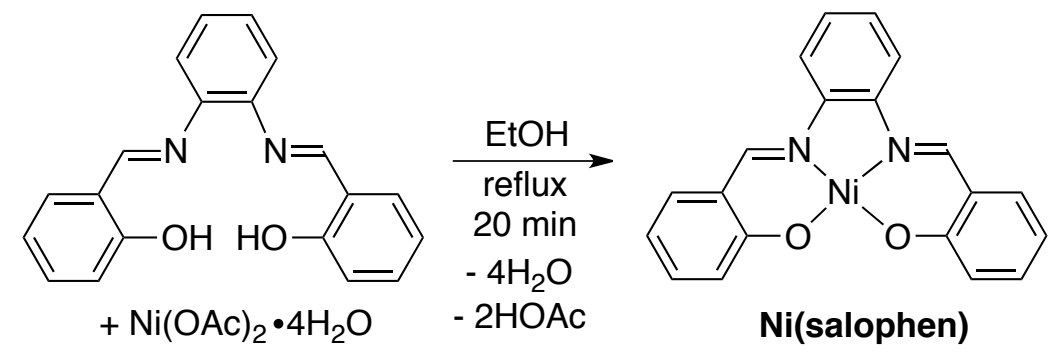

Week 3: Synthesis of the $\mathrm{H}_{2}$ salophan Ligand and the Corresponding Nickel Complex

By the third week, students should be proficient with the synthetic techniques, making it feasible to complete the synthesis and characterization of a new ligand and a new nickel complex in one laboratory session. The reduction of $\mathrm{H}_{2}$ salophen to $\mathrm{H}_{2}$ salophan can be accomplished by using excess $\mathrm{NaBH}_{4}$ followed by a hydrolytic work-up. Most literature procedures employ methanol as the solvent for this reaction, ${ }^{12}$ likely due to the higher solubility of $\mathrm{NaBH}_{4}$ methanol $(13 \mathrm{~g} / 100 \mathrm{~mL})$ than in ethanol $(3.16 \mathrm{~g} / 100 \mathrm{~mL}) .{ }^{13}$ However, Atwood and co-workers reported that the reduction in ethanol also occurred at a reasonably fast rate. ${ }^{14}$ Given the lower toxicity and flammability, ethanol was chosen as the reaction medium (eq 4). The progress of the reduction can be visualized, as the product is colorless in ethanol. Typically, it takes ca. 20 min for the orange color of $\mathrm{H}_{2}$ salophen to fade completely. The desired $\mathrm{H}_{2}$ salophan ligand precipitates from the reaction mixture upon treatment with water. The solid can be collected by vacuum filtration, rinsed with distilled water and hexanes, and then air-dried at room temperature. Our characterization methods once again relied primarily on ${ }^{1} \mathrm{H}$ NMR, ${ }^{13} \mathrm{C}\left\{{ }^{1} \mathrm{H}\right\} \mathrm{NMR}$, and IR spectroscopy.
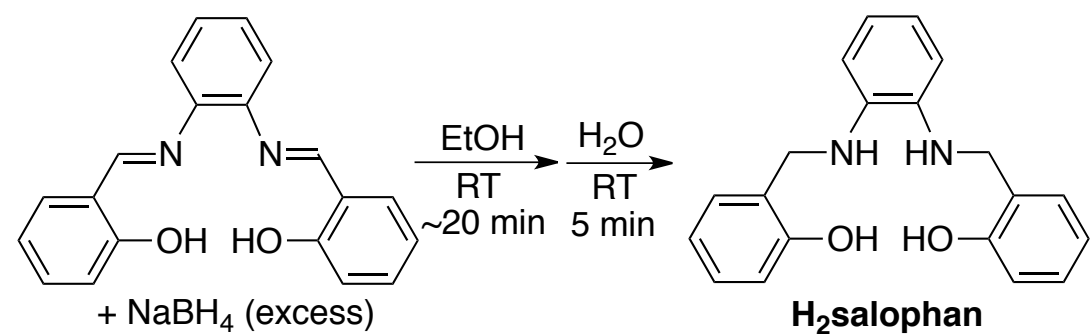

For comparison, complexation of $\mathrm{Ni}(\mathrm{OAc})_{2} \bullet 4 \mathrm{H}_{2} \mathrm{O}$ with $\mathrm{H}_{2}$ salophan should be performed following the procedure identical to the one used for $\mathrm{H}_{2}$ salophen. Students are likely self-convinced that the reaction gives $\mathrm{Ni(salophan),} \mathrm{analogous} \mathrm{to} \mathrm{the} \mathrm{formation} \mathrm{of} \mathrm{Ni(salophen)} \mathrm{(eq} \mathrm{5).} \mathrm{They} \mathrm{will,}$ however, notice something different from the Week 2 experiment: the reaction mixture turns into a 
green solution first but quickly forms a precipitate, which, after the typical work-up steps (i.e., filtration, washing, and drying), yields a light-blue solid. Unlike Ni(salophen), the presumed "Ni(salophan)" does not dissolve in $\mathrm{CDCl}_{3}$ or $\mathrm{C}_{6} \mathrm{D}_{6}$. It is only sparingly soluble in acetone and acetonitrile, but readily soluble in dimethylformamide (DMF). While it is cost prohibitive to obtain the NMR spectra, the isolated compound can be characterized by IR spectroscopy.
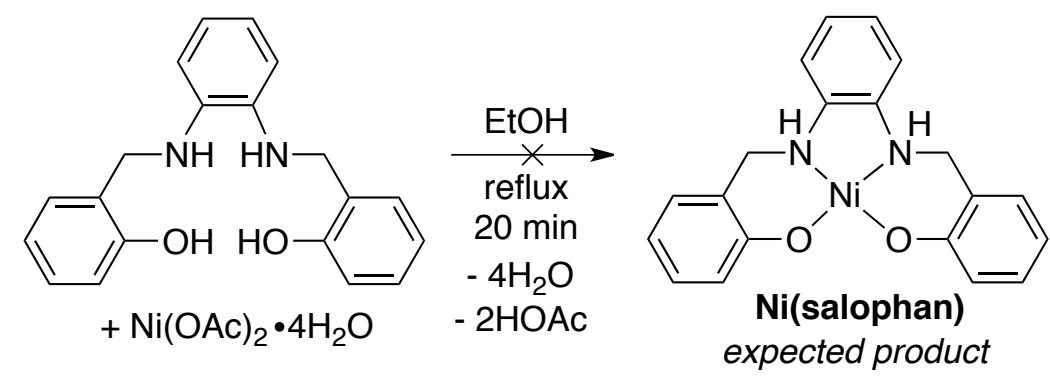

Despite the lack of NMR data, the light-blue color suggested to us that the isolated nickel complex was not Ni(salophan) with a square planar geometry as shown in eq 5 . Students were asked to prepare samples of this unknown compound in acetone, acetonitrile, and DMF (exposed to air) with the intention to grow single crystals for crystallographic analysis. In the meantime, one sample from the class was submitted for mass spectral and elemental analyses, which were expected to provide additional structural information.

After 3 weeks of experiments, students already have sufficient data to write a complete story in a lab report, which ideally should follow the format of a scientific paper (see Supporting Information for instructions). Students should be strongly encouraged to use a chemical database such as SciFinder to search relevant references. If a web search engine is used, they should be advised to read the primary literature.

\section{Weeks 4 and 5: Further Investigation of the Nickel Complex Derived from $\mathrm{H}_{2}$ Salophan}

In actuality, when we implemented the experiments, two weeks elapsed after Week 3. Depending on the availability of instrumentation or the promptness of analytical services, this brief hiatus in the project may or may not be needed. We used the gap time to ask students to prepare the related $\mathrm{Co}\left(\right.$ salophen) and $\mathrm{Cu}\left(\right.$ salophen) complexes, ${ }^{11 a}$ but for the scope of this paper, these experiments will not be discussed. Alternatively, instructors may consider additional physical methods to characterize 
the compounds made in Weeks 1-3 (e.g., UV-Vis spectroscopy, melting point, magnetic susceptibility, and cyclic voltammetry) while waiting for the EA and MS data or single crystals to grow.

It is important to engage students in the discussion of potential structures for the light-blue compound that they made in Week 3. Figure 1 shows several structures proposed by the students after hinting that ligands originated from $\mathrm{Ni}(\mathrm{OAc})_{2} \bullet 4 \mathrm{H}_{2} \mathrm{O}$ may remain bounded. Some students may find literature precedents supporting structures $\mathbf{A}^{15}$ and B. ${ }^{16}$ The latter is even more convincing because the described color matches with our observation. However, the EA data argue against the formulae $\mathrm{Ni}\left(\right.$ salophan) (A), $\mathrm{Ni}\left(\right.$ salophan) $\left(\mathrm{H}_{2} \mathrm{O}\right)_{2}(\mathbf{B})$, and $\mathrm{Ni}($ salophan)(HOAc) 2 (C), and instead support the formula Ni(salophan)(HOAc) (D). The presence of acetate can be further confirmed by the MS and IR data. While the exact structure is still a mystery, it is clear that the saturated $\mathrm{N}_{2} \mathrm{O}_{2}$ ligand does not confer a rigid square planar geometry favoring a complete loss of the acetate.

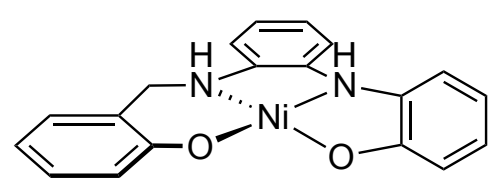

A

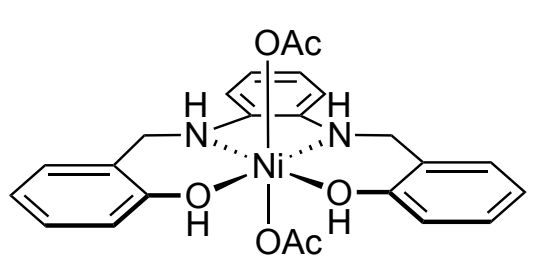

C

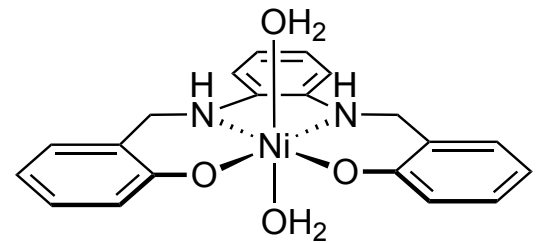

B

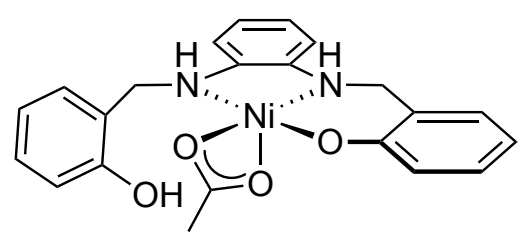

Figure 1. Potential structures for the light-blue complex synthesized from $\mathrm{Ni}(\mathrm{OAc})_{2} \bullet 4 \mathrm{H}_{2} \mathrm{O}$ and $\mathrm{H}_{2}$ salophan (ligand coordination mode may vary).

For the samples dissolved in acetone and acetonitrile, students will notice a color change from almost colorless (due to low concentrations) to orange or red in a week. The sample prepared in DMF turns to green quickly and then to dark red in less than $24 \mathrm{~h}$. Students are most likely to obtain single crystals from slow evaporation of the DMF solution; the key is to use as little DMF as possible to dissolve the unknown compound. In the event that students fail to produce crystals suited for X-ray 
study, instructors may consider asking students to prepare a saturated solution of Ni(salophen) in hot ethanol, which yields single crystals readily upon cooling and evaporation. This back-up plan does not shed light on the structure of the unknown compound but still gives students the opportunity to learn X-ray crystallography using their own samples.

In Week 4, students are divided into two groups: one solving the crystal structure and the other attempting another synthesis of $\mathrm{Ni(salophan).} \mathrm{They} \mathrm{switch} \mathrm{the} \mathrm{activities} \mathrm{in} \mathrm{the} \mathrm{following} \mathrm{week.}$ Such division may or may not be needed, depending on logistics and class size. If an X-ray diffractometer is unavailable for instructional use, the entire class can focus on the synthesis only.

In the X-ray lab, students learn various morphologies of solid samples and, under a microscope, identify crystals suitable for X-ray diffraction. Other training activities include mounting a crystal and transferring it to the goniostat of the diffractometer for data collection. Given the time constraint, a pre-acquired data set shall be provided to the students so that they can learn how to use the SHELX suite of programs to solve a structure. Crystal lattices and unit cells are often covered in the lecture-based Inorganic Chemistry course; they can be refreshed in the laboratory.

In the synthetic lab, students repeat the reaction in eq 5 except that $\mathrm{NaOH}(0.1 \mathrm{M}$ in water $)$ is also added to assist the elimination of HOAc. Students can be instructed to do so, although it is more beneficial to guide them to this path by asking them what modification to the procedures should be made in order to obtain $\mathrm{Ni}($ salophan). Knowing that the unknown compound has the formula $\mathrm{Ni}$ (salophan)(HOAc), students may propose to use a base such as $\mathrm{NaOH}, \mathrm{Na}_{2} \mathrm{CO}_{3}$, or Et ${ }_{3} \mathrm{~N}$ to remove HOAc while driving the reaction to form Ni(salophan). The inquiry-guided experimental design also leads to discussion about the amount of base used (1 or 2 equiv) and the starting materials employed (the light-blue unknown compound or $\mathrm{H}_{2}$ salophan/ $\left.\mathrm{Ni}(\mathrm{OAc})_{2} \bullet 4 \mathrm{H}_{2} \mathrm{O}\right)$. These variations to the procedures can of course all be tested, preferably by students working in pairs or groups. For simplicity, we had the entire class perform the synthesis using a $1: 1: 2$ mixture of $\mathrm{H}_{2}$ salophan, $\mathrm{Ni}(\mathrm{OAc})_{2} \bullet 4 \mathrm{H}_{2} \mathrm{O}$, and $\mathrm{NaOH}$. The isolated product is no longer a light-blue solid but a rust-colored powder, which can be analyzed by both ${ }^{1} \mathrm{H}$ NMR and IR spectroscopy. 


\section{HAZARDS}

Students must wear safety glasses, lab coats, and nitrile gloves while working in the laboratory. As pre-lab preparation, they are also required to read SDS information for the chemicals to be used. Handling some of these chemicals requires extra precaution. In particular, o-phenylenediamine is very toxic to aquatic life and harmful when in contact with skin or if inhaled. $\mathrm{CDCl}_{3}$ is toxic if inhaled and suspected of causing cancer. $\mathrm{Ni}(\mathrm{OAc})_{2} \bullet 4 \mathrm{H}_{2} \mathrm{O}$ is a known carcinogen and may cause allergic skin reaction. All nickel complexes made by the students should also be treated as such, considering that the safety information regarding complexes is very limited in the literature. $\mathrm{NaBH}_{4}$ should be kept in a dry place, ideally under an inert atmosphere. Special care should be taken to ensure that it does not make contact with water during storage, which may release flammable gases. Salicylaldehyde and organic solvents used in the study including EtOH, Et $2 \mathrm{O}$, and hexanes are flammable and easily ignited by heat, spark, or flames. A stock solution of $\mathrm{NaOH}$ is used for the final synthesis; though the concentration is relatively low $(0.1 \mathrm{M})$, students should be reminded that it can be corrosive and cause skin irritation and eye damage. All X-ray equipment present hazards. Trained personnel should be present in the X-ray laboratory to ensure students behave safely and to conduct the manipulations on the diffractometer. ${ }^{17}$

\section{RESULTS AND DISCUSSION}

The ${ }^{1} \mathrm{H}$ NMR spectra of $\mathrm{H}_{2}$ salophen, $\mathrm{Ni}$ (salophen), and $\mathrm{H}_{2}$ salophan are most informative for judging success of the syntheses and purity of the products. In $\mathrm{CDCl}_{3}, \mathrm{H}_{2}$ salophen shows several aromatic resonances in the $6.90-7.40 \mathrm{ppm}$ range, an imine $\mathrm{CH}=\mathrm{N}$ resonance at $8.63 \mathrm{ppm}$, and an $\mathrm{O} H$ resonance at $13.05 \mathrm{ppm}$. The latter is shifted downfield from the $\mathrm{OH}$ resonance of a typical phenol-type compound (4-7 ppm), which can be rationalized by the presence of intramolecular hydrogen bonds (OH...N). ${ }^{9}$ Nevertheless, the molecule is symmetric, displaying 10 different carbon resonances as expected for the structure shown in eq 2. Students should be given reference NMR spectra of $o-$ phenylenediamine and salicylaldehyde as well as the data for common NMR impurities, ${ }^{18}$ which will help them identify the cause for an impure product. Complexation of $\mathrm{Ni}(\mathrm{OAc})_{2} \bullet 4 \mathrm{H}_{2} \mathrm{O}$ with $\mathrm{H}_{2}$ salophen is evident from the ${ }^{1} \mathrm{H}$ NMR spectrum of the isolated product, where the $\mathrm{O} H$ resonance is absent and 
the imine $\mathrm{CH}=\mathrm{N}$ resonance is shifted to $8.26 \mathrm{ppm}$ (in $\mathrm{CDCl}_{3}$ ). The imine carbon resonance is also shifted upfield from $163.8 \mathrm{ppm}$ in $\mathrm{H}_{2}$ salophen to $154.4 \mathrm{ppm}$ in $\mathrm{Ni}(\mathrm{salophen})$. The remaining proton and carbon resonances are similar to those for the ligand but sufficiently different to conclude that a nickel complex is made. Reduction of $\mathrm{H}_{2}$ salophen to $\mathrm{H}_{2}$ salophan is confirmed by the disappearance of the imine $\mathrm{CH}=\mathrm{N}$ resonance and the observation of a singlet at $4.41 \mathrm{ppm}$ attributed to the $\mathrm{CH}_{2}-\mathrm{NH}$ resonance. The $\mathrm{OH}$ and $\mathrm{NH}$ resonances of $\mathrm{H}_{2}$ salophan appear at 7.85 and $3.72 \mathrm{ppm}$, respectively. Students who fail to dry the product thoroughly may see significant broadening and/or slight shifting of these two resonances, which results from a rapid proton exchange with ethanol or water. The success of imine reduction is further supported by the observation of a carbon resonance at $47.9 \mathrm{ppm}$ for the methylene group in $\mathrm{H}_{2}$ salophan.

Assigning all IR bands is unrealistic; however, when given a chart of IR frequency ranges for various vibration modes, ${ }^{19}$ students are able to identify the more characteristic $\mathrm{N}-\mathrm{H}, \mathrm{C}-\mathrm{H}, \mathrm{C}=\mathrm{N}$, and C$\mathrm{O}$ stretching bands. For example, the $\mathrm{C}=\mathrm{N}$ band is located at $1609 \mathrm{~cm}^{-1}$ for $\mathrm{H}_{2}$ salophen and $1602 \mathrm{~cm}^{-1}$ for $\mathrm{Ni}\left(\right.$ salophen). Due to hydrogen-bonding interactions, the $\mathrm{O}-\mathrm{H}$ bands in $\mathrm{H}_{2}$ salophen and $\mathrm{H}_{2}$ salophan are too broad to be definitively assigned. In contrast, the $\mathrm{N}-\mathrm{H}$ band of $\mathrm{H}_{2}$ salophan is observed at $3287 \mathrm{~cm}^{-1}$.

According to the EA data, $\mathrm{Ni}(\mathrm{salophan})(\mathrm{HOAc})$ is the formula for the light-blue compound isolated from the reaction of $\mathrm{H}_{2}$ salophan with $\mathrm{Ni}(\mathrm{OAc})_{2} \bullet 4 \mathrm{H}_{2} \mathrm{O}$. The presence of acetate is also supported by IR spectroscopy, which shows medium intensity bands at 1555 and $1424 \mathrm{~cm}^{-1}$ for the unsymmetrical and symmetrical C-O stretches, respectively. ${ }^{20}$ Two weak bands are found in the region for $\mathrm{O}-\mathrm{H} / \mathrm{N}-\mathrm{H}$ stretches $\left(3213\right.$ and $3160 \mathrm{~cm}^{-1}$ ), though on the lower end. Under MS conditions (electrospray ionization, in ethanol), this compound gives mass ions corresponding to Ni(salophan)H $\left(\mathrm{MH}^{+}\right)$, aggregates $\mathrm{M}_{2} \mathrm{H}^{+}$and $\mathrm{M}_{3} \mathrm{H}^{+}$, and two acetate-containing species $[\mathrm{M}(\mathrm{NiOAc})]^{+}$and $\left[\mathrm{M}_{2}(\mathrm{NiOAc})\right]^{+}$. These data are in agreement with structure $\mathbf{D}$ in Figure 1 or its isomer involving $\kappa^{1}$ or free $[\mathrm{OAc}]^{-}$or with the [Hsalophan]- ligand adopting a different coordination mode. The mass spectrum also reveals an ion for $[\mathrm{MH}-2 \mathrm{H}]^{+}$, suggesting that the compound undergoes dehydrogenation readily.

In fact, the light-blue compound dissolved in acetone, acetonitrile, or DMF changes color to red over time. The crystals grown from DMF solve as Ni(salophen) (Figure 2), ${ }^{21,22}$ indicating that 
dehydrogenation of the ligand backbone indeed has occurred. The rust-colored powder isolated from the reaction of $\mathrm{H}_{2}$ salophan with $\mathrm{Ni}(\mathrm{OAc})_{2} \bullet 4 \mathrm{H}_{2} \mathrm{O}$ and 2 equiv of $\mathrm{NaOH}$ is consistent with $\mathrm{Ni}($ salophan), which is supported by the IR data (one $\mathrm{O}-\mathrm{H} / \mathrm{N}-\mathrm{H}$ band at $3261 \mathrm{~cm}^{-1}$ and the lack of acetate).

However, $\sim 50 \%$ of the students in our class obtained a material analyzed as a mixture of Ni(salophan) and $\mathrm{Ni}\left(\right.$ salophen). In any case, the rust-colored powder is partially soluble in $\mathrm{CDCl}_{3}$ and the dissolved species is confirmed as Ni(salophen). Taken together, these results suggest that both $\mathrm{Ni}($ salophan)(HOAc) and $\mathrm{Ni}($ salophan) can be readily converted to the more stable Ni(salophen), especially in the presence of a base and under heating. Students who obtained the mixture of $\mathrm{Ni}($ salophan) and Ni(salophen) for the final synthesis likely had excessive heating. Understanding the exact mechanism for the ligand dehydrogenation requires additional investigation. It is possible that the nickel-bound amido group undergoes $\beta$-hydride elimination (followed by protonation of the resulting nickel hydride), which is a topic typically covered in the organometallic chapter of most inorganic textbooks.

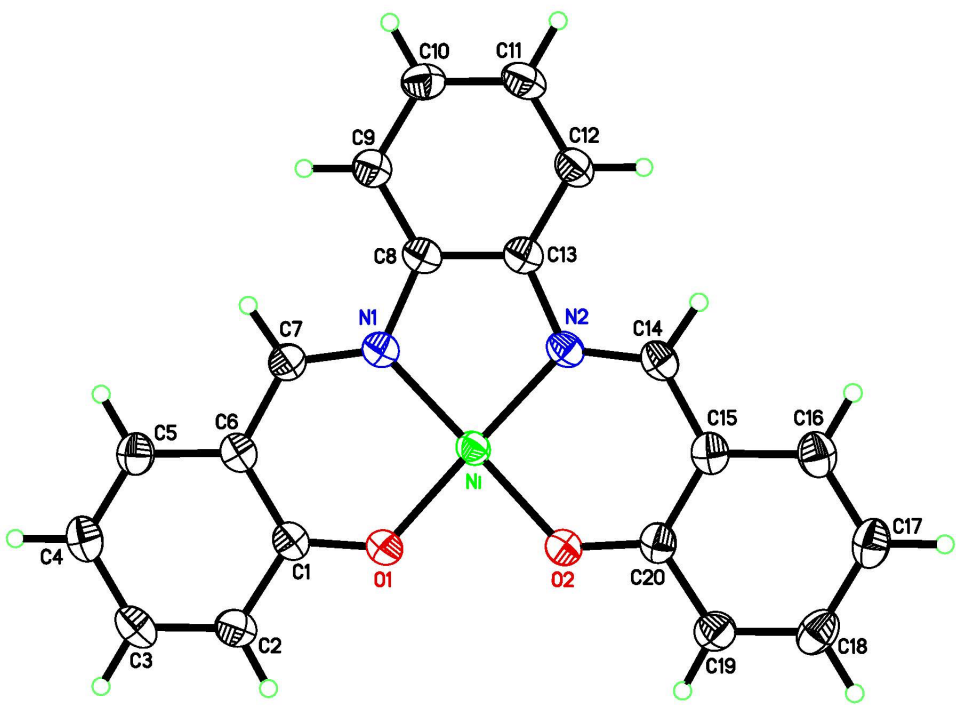

Figure 2. ORTEP drawing of Ni(salophen) at the 50\% probability level.

\section{SUMMARY}

The reactivity and stability of inorganic compounds are highly dependent on the donor properties and ligand flexibility, even if the same set of donor atoms are involved. This is well illustrated here for a $\mathrm{Ni}$ (II) system supported by an $\mathrm{N}_{2} \mathrm{O}_{2}$ tetradentate ligand. The experiments initially focus on training 
students in synthetic techniques and physical methods, and then transition to an open-ended project that requires them to apply learned knowledge to solve a chemistry mystery. In addition to developing critical thinking skills, students also gain a research-focused experience, which is typically unavailable in a course simply using procedures drawn from a laboratory manual. Furthermore, students become more critical in reading the literature, as they will find that published data could be wrong or misinterpreted. The ligands are simple and can be slightly altered if desired (e.g., using a different diamine or salicylaldehyde derivative as the starting material). Given the rich coordination chemistry of salen-type complexes, the course materials can also be expanded to semester-long experiments (e.g., studying different metal systems $\left.{ }^{6,11 a, 23}\right)$.

\section{ASSOCIATED CONTENT}

10.1021/acs.jchemed.xxxxxxx

Instructions for students (PDF, DOCX)

Notes for instructors (PDF, DOCX)

\section{AUTHOR INFORMATION}

Corresponding Author

*E-mail: hairong.guan@uc.edu

\section{ACKNOWLEDGMENTS}

The authors thank the Department of Chemistry at the University of Cincinnati and the NSF Chemical Catalysis Program (CHE-1800151) for financial support, Dr. Larry Sallans at the University of Cincinnati for assistance with mass spectral analysis, and the NSF MRI Program for instrumental support, which includes the purchase of two Bruker single-crystal diffractometers (CHE-0215950 and CHE-1625737) and a Bruker NEO400 MHz NMR spectrometer (CHE-1726092).

\section{REFERENCES}

${ }^{1}$ Erxleben, A. Transition Metal Salen Complexes in Bioinorganic and Medicinal Chemistry. Inorg. Chim. Acta 2018, 472, 40-57. https:/doi.org/10.1016/j.ica.2017.06.060. 
2 (a) Muller, J. G.; Paikoff, S. J.; Rokita, S. E.; Burrows, C. J. DNA Modification Promoted by WaterSoluble Nickel(II) Salen Complexes: A Switch to DNA Alkylation. J. Inorg. Biochem. 1994, 54, 199-206. https:/doi.org/10.1016/0162-0134(94)80013-8. (b) Czlapinski, J. L.; Sheppard, T. L. Nucleic Acid Template-Directed Assembly of Metallosalen-DNA Conjugates. J. Am. Chem. Soc. 2001, 123, 86188619. https:/doi.org/10.1021/ja0162212. (c) Giannicchi, I.; Brissos, R.; Ramos, D.; de Lapuente, J.; Lima, J. C.; Dalla Cort, A.; Rodriguez, L. Substituent Effects on the Biological Properties of ZnSalophen Complexes. Inorg. Chem. 2013, 52, 9245-9253. https:/doi.org/10.1021/ic4004356. (d) Majumder, S.; Pasayat, S.; Panda, A. K.; Dash, S. P.; Roy, S.; Biswas, A.; Varma, M. E.; Joshi, B. N.; Garribba, E.; Kausar, C.; Patra, S. K.; Kaminsky, W.; Crochet, A.; Dinda, R. Monomeric and Dimeric Oxidomolybdenum(V and VI) Complexes, Cytotoxicity, and DNA Interaction Studies: Molybdenum Assisted C=N Bond Cleavage of Salophen Ligands. Inorg. Chem. 2017, 56, 11190-11210. https:/doi.org/10.1021/acs.inorgchem.7b01578.

${ }^{3}$ (a) Canali, L.; Sherrington, D. C. Utilisation of Homogeneous and Supported Chiral Metal(salen) Complexes in Asymmetric Catalysis. Chem. Soc. Rev. 1999, 28, 85-93.

https:/doi.org/10.1039/a806483k. (b) Jacobsen, E. N. Asymmetric Catalysis of Epoxide Ring-Opening Reactions. Acc. Chem. Res. 2000, 33, 421-431. https:/doi.org/10.1021/ar960061v. (c) Venkataramanan, N. S.; Kuppuraj, G.; Rajagopal, S. Metal-Salen Complexes as Efficient Catalysts for the Oxygenation of Heteroatom Containing Organic Compounds-Synthetic and Mechanistic Aspects. Coord. Chem. Rev. 2005, 249, 1249-1268. https:/doi.org/10.1016/j.ccr.2005.01.023. (d) Baleizão, C.; Garcia, H. Chiral Salen Complexes: An Overview to Recoverable and Reusable Homogeneous and Heterogeneous Catalysts. Chem. Rev. 2006, 106, 3987-4043. https:/doi.org/10.1021/cr050973n. ${ }^{4}$ (a) Di Bella, S.; Fragalà, I.; Ledoux, I.; Marks, T. J. Role of Metal Electronic Properties in Tuning the Second-Order Nonlinear Optical Response of Coordination Complexes. A Combined Experimental and Theoretical Investigation of a Homologous Series of ( $N, N$-Disalicylidene-1,2-phenylenediaminato) $\mathrm{M}$ (II) $(\mathrm{M}=\mathrm{Co}, \mathrm{Ni}, \mathrm{Cu})$ Complexes. J. Am. Chem. Soc. 1995, 117, 9481-9485.

https:/doi.org/10.1021/ja00142a014. (b) Wezenberg, S. J.; Kleij, A. W. Material Applications for Salen Frameworks. Angew. Chem. Int. Ed. 2008, 47, 2354-2364. https:/doi.org/10.1002/anie.200702468. (c) Gao, F.; Li, J.; Kang, F.; Zhang, Y.; Wang, X.; Ye, F.; Yang, J. Preparation and Characterization of a Poly[Ni(salen)]/Multiwalled Carbon Nanotube Composite by in Situ Electropolymerization as a Capacitive Material. J. Phys. Chem. C 2011, 115, 11822-11829. https:/doi.org/10.1021/ip111831y. ${ }^{5}$ (a) Atwood, D. A.; Jegier, J. A.; Lindholm, N. F.; Martin, K. J.; Rutherford, D. Synthesis, Structure and Reactivity of SalanH 2 -Metal Complexes. J. Coord. Chem. 1996, 38, 305-318. https:/doi.org/10.1080/00958979608024525. (b) Belaid, S.; Landreau, A.; Djebbar, S.; BenaliBaitich, O.; Bouet, G.; Bouchara, J.-P. Synthesis, Characterization and Antifungal Activity of a Series of Manganese(II) and Copper(II) Complexes with Ligands Derived from Reduced $N, N^{\prime}-O-$ phenylenebis(salicylideneimine). J. Inorg. Biochem. 2008, 102, 63-69.

https:/doi.org/10.1016/i.jinorgbio.2007.07.001. (c) Zhou, X.-F. Catalytic Oxidation and Conversion of Kraft Lignin into Phenolic Products Using Zeolite-Encapsulated Cu(II) [H4] salen and $\left[\mathrm{H}_{2}\right]$ salen Complexes. Environ. Prog. Sustain. Energy 2015, 34, 1120-1128. https:/doi.org/10.1002/ep. 12092. (d) Reytman, L.; Braitbard, O.; Hochman, J.; Tshuva, E. Y. Highly Effective and Hydrolytically Stable Vanadium(V) Amino Phenolato Antitumor Agents. Inorg. Chem. 2016, 55, 610-618. https:/doi.org/10.1021/acs.inorgchem.5b02519. (e) Zhao, X.; Zhang, D.; Yu, R.; Chen, S.; Zhao, D. Tetrahydrosalen Uranyl(VI) Complexes: Crystal Structures and Solution Binding Study. Eur. J. Inorg. Chem. 2018, 1185-1191. https:/doi.org/10.1002/ejic.201701401.

${ }^{6}$ (a) Appleton, T. G. Oxygen Uptake by a Cobalt(II) Complex. An Undergraduate Experiment. J. Chem. Educ. 1977, 54, 443-444. https:/doi.org/10.1021/ed054p443. (b) Vecchio, G.; Lanza, V. Synthesis of Superoxide Dismutase (SOD) Enzyme Mimetics. A Bioinorganic Laboratory Experiment. J. Chem. Educ. 2009, 86, 1419-1421. https:/doi.org/10.1021/ed086p1419.

7 In earlier years, we implemented similar experiments with the $\mathrm{H}_{2}$ salen ligand, and found that some students would simply use Google to search for answers to pre-lab and post-lab questions. This practice has its merit but can be dangerous for learning because of the prevalence of misinformation on the Internet. One example is the chemical structure of $\mathrm{Ni}(\mathrm{salen})$ erroneously provided on a vendor's website: https://www.sigmaaldrich.com/catalog/product/aldrich/268658?lang=en\&region=US 
(accessed August 25, 2020).

8 (a) Hernández-Benítez, L. J.; Jiménez-Cruz, P.; Cureño-Hernández, K. E.; Solano-Peralta, A.; FloresÁlamo, M.; Flores-Parra, A.; Garcia-Mora, I.; Castillo-Blum, S. E. [VIVO] ${ }^{2+}$ Complexes: Structure, Unusual Magnetic Properties and Cytotoxic Effect. Inorg. Chim. Acta 2018, 480, 197-206.

https:/doi.org/10.1016/j.ica.2018.05.013. (b) Asraf, M. A.; Ezugwu, C. I.; Zakaria, C. M.; Verpoort, F. Homogeneous Photochemical Water Oxidation with Metal Salophen Complexes in Neutral Media. Photochem. Photobiol. Sci. 2019, 18, 2782-2791. https:/doi.org/10.1039/c9pp00254e. (c) Li, N.; Wang, Y.; Liu, F.; Zhao, X.; Xu, X.; An, Q.; Yun, K. Air-Stable Zirconium (IV)-Salophen

Perfluorooctanesulfonate as a Highly Efficient and Reusable Catalyst for the Synthesis of 3,4Dihydropyrimidin-2- $(1 \mathrm{H})$-ones/Thiones Under Solvent-Free Conditions. Appl. Organometal. Chem. 2020, 34, e5454. https:/doi.org/10.1002/aoc.5454.

9 Deng, H.; Liu, B.; Yang, C.; Li, G.; Zhuang, Y.; Li, B.; Zhu, X. Multi-Color Cell Imaging Under Identical Excitation Conditions with Salicylideneaniline Analogue-Based Fluorescent Nanoparticles. RSC Adv. 2014, 4, 62021-62029. https:/doi.org/10.1039/c4ra10021b.

10 If room temperature is preferred, students should be reminded that good mixing is the key to success for the synthesis. Otherwise, the isolated product may contain a small amount of the unreacted o-phenylenediamine (5\%).

11 (a) Hille, A.; Ott, I.; Kitanovic, A.; Kitanovic, I.; Alborzinia, H.; Lederer, E.; Wölfl, S.; Metzler-Nolte, N.; Schäfer, S.; Sheldrick, W. S.; Bischof, C.; Schatzschneider, U.; Gust, R. [N,N'-Bis(salicylidene)-1,2phenylenediamine]metal Complexes with Cell Death Promoting Properties. J. Biol. Inorg. Chem. 2009 14, 711-725. https:/doi.org/10.1007/s00775-009-0485-9. (b) Jamshid, K. A., Asadi, M.; Kianfar, A. H. Synthesis, Characterization and Thermal Studies of Dinuclear Adducts of Diorganotin(IV) Dichlorides with Nickel(II) Schiff-Base Complexes in Chloroform. J. Coord. Chem. 2009. 62, $1187-$ 1198. https:/doi.org/10.1080/00958970802363974. (c) Lee, S.-Y.; Hille, A.; Frias, C.; Kater, B.; Bonitzki, B.; Wölfl, S.; Scheffler, H.; Prokop, A.; Gust, R. [NiII(3-OMe-salophene)]: A Potent Agent with Antitumor Activity. J. Med. Chem. 2010, 53, 6064-6070. https:/doi.org/10.1021/jm100459k.

12 (a) Magro, A.; Crociani, L.; Prinzivalli, C.; Vigato, P. A.; Zanonato, P. L.; Tamburini, S. Coordination Ability of Free or Silica Immobilized Schiff Bases Towards $\mathrm{Hg}(\mathrm{II}), \mathrm{Cd}(\mathrm{II})$ and $\mathrm{Pb}(\mathrm{II})$ Ions. Inorg. Chim. Acta 2014, 410, 29-38. https:/doi.org/10.1016/i.ica.2013.10.005. (b) Tayade, K.; Sahoo, S. K.; Patil, R.; Singh, N.; Attarde, S.; Kuwar, A. 2,2'-[Benzene-1,2-diylbis(iminomethanediyl)]diphenol Derivative Bearing Two Amine and Hydroxyl Groups as Fluorescent Receptor for Zinc(II) Ion. Spectrochim. Acta A 2014, 126, 312-316. https:/doi.org/10.1016/j.saa.2014.02.003. (c) Dadkhah, M.; Salavati-Niasari, M.; Mir, N. Synthesis and Characterization of $\mathrm{TiO}_{2}$ Nanoparticles by Using New Shape Controllers and Its Application in Dye Sensitized Solar Cells. J. Ind. Eng. Chem. 2014, 20, 4039-4044.

https:/doi.org/10.1016/j.jiec.2014.01.003. (d) Ding, Z.; Yang, Y. Dioxovanadium(V) Complexes of Schiff and Tetrahydro-Schiff Bases Encapsulated in Zeolite-Y for the Aerobic Oxidation of Styrene. Kinet. Catal. 2017, 58, 290-299. https:/doi.org/10.1134/S0023158417030053.

13 Banfi, L.; Narisano, E.; Riva, R. Sodium Borohydride. In Encyclopedia of Reagents for Organic Synthesis; John Wiley \& Sons: New York, 2001. https:/doi.org/10.1002/047084289X.rs052.

${ }_{14}$ Atwood, D. A.; Benson, J.; Jegier, J. A.; Lindholm, N. F.; Martin, K. J.; Pitura, R. J.; Rutherford, D. Synthesis and Structural Characterization of Tetradentate $\left(\mathrm{N}_{2} \mathrm{O}_{2}\right)$ Ligand Complexes of Zinc. Main Group Chem. 1995, 1, 99-113. https:/doi.org/10.1080/13583149512331338305.

15 Salavati-Niasari, M.; Shakouri-Arani, M.; Davar, F. Flexible Ligand Synthesis, Characterization and Catalytic Oxidation of Cyclohexane with Host (Nanocavity of Zeolite-Y)/Guest (Mn(II), Co(II), Ni(II) and $\mathrm{Cu}(\mathrm{II})$ Complexes of Tetrahydro-Salophen) Nanocomposite Materials. Microporous Mesoporous Mater. 2008, 116, 77-85. https:/doi.org/10.1016/j.micromeso.2008.03.015.

16 Aidyn, A.; Medzhidov, A. A.; Fatullaeva, P. A.; Tashchioglu, S.; Yalchin, B.; Saiyn, S. Oxidative

Dehydrogenation in Complexes of Transition Metals (Cu(II), Co(II), Ni(II)) with N,N'-Di(2-

Hydroxybenzyl)diamines. Russ. J. Coord. Chem. 2001, 27, 486-492.

https:/doi.org/10.1023/A:1011389632581.

17 To perform the manipulations on the diffractometer, all users must undergo University of Cincinnati radiation safety and site-specific diffractometer training. Sessions are held in the Richard C. Elder Xray Crystallography Facility. 
18 Fulmer, G. R.; Miller, A. J. M.; Sherden, N. H.; Gottlieb, H. E.; Nudelman, A.; Stoltz, B. M.; Bercaw, J. E.; Goldberg, K. I. NMR Chemical Shifts of Trace Impurities: Common Laboratory Solvents, Organics, and Gases in Deuterated Solvents Relevant to the Organometallic Chemist. Organometallics 2010, 29, 2176-2179. https://doi.org/10.1021/om100106e.

19 A useful source of IR spectrum table can be found from the Sigma-Aldrich website: https://www.sigmaaldrich.com/technical-documents/articles/biology/ir-spectrum-table.html (accessed August 25, 2020).

20 Jones, L. H.; McLaren, E. Infrared Spectra of $\mathrm{CH}_{3} \mathrm{COONa}$ and $\mathrm{CD}_{3} \mathrm{COONa}$ and Assignments of Vibrational Frequencies. J. Chem. Phys. 1954, 22, 1796-1800. https://doi.org/10.1063/1.1739921. 21 The unit cell matches Ni(salopen) reported in the literature, although our data were collected using both $\mathrm{Cu} \mathrm{K} \alpha$ and $\mathrm{Mo} \mathrm{K} \alpha$ radiation and at a different temperature (150 K instead of $100 \mathrm{~K}$ and $296 \mathrm{~K})$. Students were divided into two groups: one group solved the $\mathrm{Cu} \mathrm{K \alpha}$ data and the other solved the Mo $\mathrm{K} \alpha$ data. They were asked to compare the results and determine whether radiation type influenced the results obtained. For references, see: (a) Chowdhury, B.; Karar, M.; Paul, S.; Joshi, M.; Choudhury, A. R.; Biswas, B. Salen Type Ligand as a Selective and Sensitive Nickel(II) Ion Chemosensor: A Combined Investigation with Experimental and Theoretical Modelling. Sens. Actuator B Chem. 2018, 276, 560566. https://doi.org/10.1016/j.snb.2018.08.141. (b) Ansari, R. M.; Kumar, L. M.; Bhat, B. R. AirStable Cobalt(II) and Nickel(II) Complexes with Schiff Base Ligand for Catalyzing Suzuki-Miyaura Cross-Coupling Reaction. Russ. J. Coord. Chem. 2018, 44, 1-8. https://doi.org/10.1134/S1070328418010013.

${ }^{22}$ Krause, J. A.; Al-Khasawneh, N. R.; Bain, T. R.; Beckes, A. E.; Bolender, A. J.; Brewer, B. J.; Conner, C. E.; Cox, S.; Harris, K.; Jiang, D.; Kile, A. O.; Merchant, M.; Steiger, P. M.; Strong, M.; Teal, W. P. A.; Zhang, Z.; Collett, J. D.; Guan, H. CSD entry: MUSWIJ; CCDC-2023070, CSD Commun. 2020. https://doi.org/ $10.5517 /$ ccdc.csd.cc25x5bm.

23 Baldwin, M. J. A Literature-Based, One-Quarter Inorganic Chemistry Laboratory Course. J. Chem. Educ. 2003, 80, 307-310. https://doi.org/10.1021/ed080p307. 